LA W RENCE LIVERMORE NATIONAL LABORATORY
Estimate of Evaporation of Uranium in Vacuum Melt Casting Systems

T. A. Shepp

August 4, 2011 
This document was prepared as an account of work sponsored by an agency of the United States government. Neither the United States government nor Lawrence Livermore National Security, LLC, nor any of their employees makes any warranty, expressed or implied, or assumes any legal liability or responsibility for the accuracy, completeness, or usefulness of any information, apparatus, product, or process disclosed, or represents that its use would not infringe privately owned rights. Reference herein to any specific commercial product, process, or service by trade name, trademark, manufacturer, or otherwise does not necessarily constitute or imply its endorsement, recommendation, or favoring by the United States government or Lawrence Livermore National Security, LLC. The views and opinions of authors expressed herein do not necessarily state or reflect those of the United States government or Lawrence Livermore National Security, LLC, and shall not be used for advertising or product endorsement purposes.

This work performed under the auspices of the U.S. Department of Energy by Lawrence Livermore National Laboratory under Contract DE-AC52-07NA27344. 


\title{
Estimate of Evaporation of Uranium in Vacuum Melt Casting Systems (U)
}

\author{
Thomas A. Shepp
}

\author{
May 2011
}

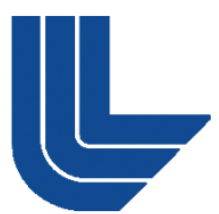

Lawrence Livermore National Laboratory is operated by Lawrence Livermore National Security, LLC, for the U.S. Department of Energy, National Nuclear Administration under Contract DE-A C52-07NA27344 


\section{Introduction}

In this document we make estimates of Uranium vapor production rates and the mass of Uranium in the vapor state during operation of a casting furnace. The information provided here is based upon the reference document:

Basic Physics of Vacuum Evaporation of Uranium with a Conventional or Advanced Melt Heating System, T. A. Shepp, LLNL Document CODT - 2011-xxxx

We assume that the melting furnace designs may include heated melts in a container with walls at a lower temperature than the melt surface and other systems with melts contained within a container at the same temperature as the melt. We assume that both systems operate in a vacuum environment.

In the first case the Uranium vapor produced at the melt surface flows from the melt to the walls where it is collected as a solid or liquid depending upon the wall temperature, In this case the Uranium vapor exists in a non-equilibrium condition. The vapor expands from the melt surface and changes in pressure, density, temperature as well as atomic excitation. Under these circumstances an ideal gas law does not provide a complete picture. For the uniform temperature case the ideal gas law can give good information on the state of the vapor.

For both cases we would like to determine an upper limit estimate of the amount of Uranium in the vapor state at any time. In the event of a breach of the containment it may also be of interest to determine the production of vapor as the melt system cools. Other vapor interactions involving a breach such as limited leaking and chemical reactions with the atmosphere all tend to limit the propagation of the vapor to occupied areas.

\section{Vacuum Chamber Pressure}

It is useful to compare typical vacuum chamber gas pressure and density to the density of the produced Uranium vapor. Following is a copy of Figure 15 from the Reference Document.

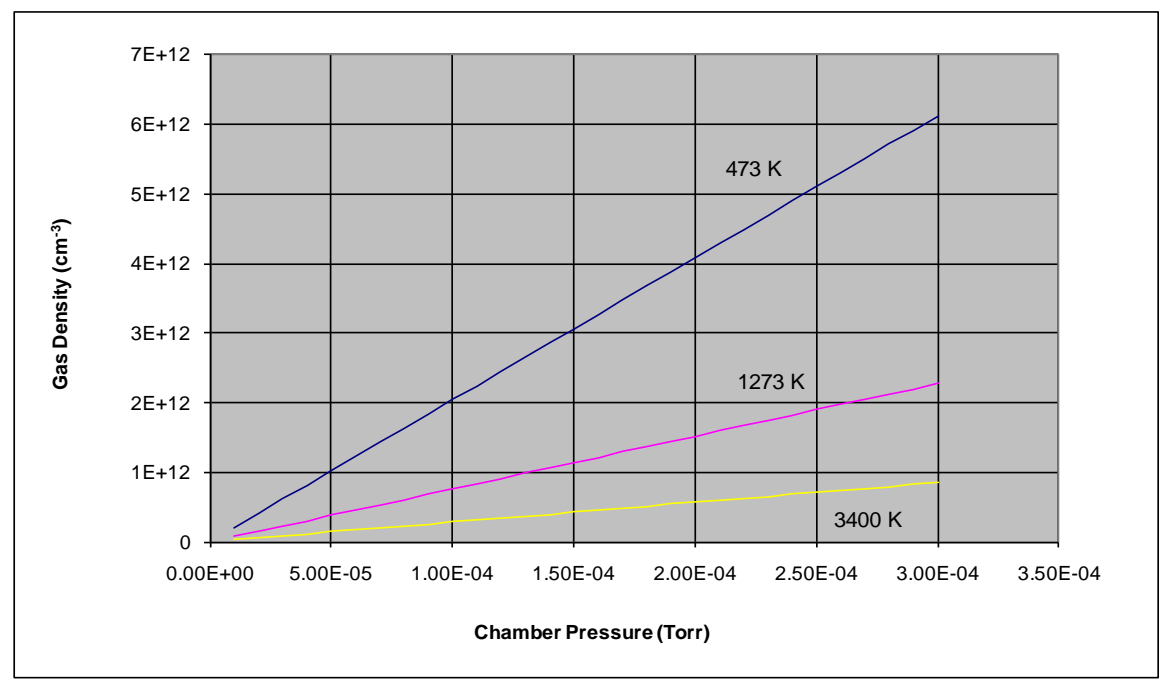

Figure 1. (Reference Figure 15) Gas density as a function of chamber pressure for three gas temperatures approximating ambient temperature $(473 \mathrm{~K})$, enclosure temperature $(1273 \mathrm{~K})$, and source temperature $(3400 \mathrm{~K})$. 


\section{Melt surface pressure}

In Figure (2) we plot the vapor pressure using Equation 5 and Table 1 from the reference document for temperatures starting at about the Uranium melting temperature up to temperatures for over-heated melts designed for casting systems. Note that for a casting melt of about $2000 \mathrm{~K}$ there is vapor produced which must be considered in the design of the system. The vapor pressure is in the range of background gas in a vacuum melt system

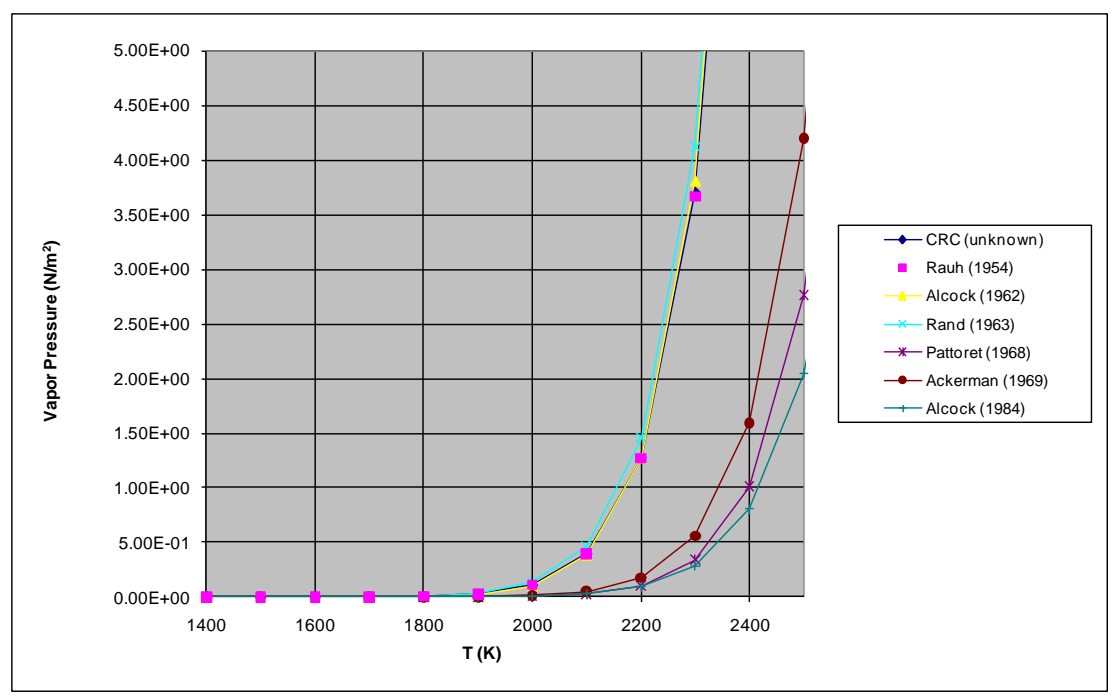

Figure 2. (Reference Figure 1) Vapor pressure for several references as a function of temperature consistent with casting melt systems.

Note that the maximum pressure of on this plot is $5 \mathrm{~N} / \mathrm{m}^{2}$ is equivalent to .0375 torr which is above the normal gas pressure in a vacuum chamber. In Figure 3 we show vapor production rates for some assumed melt sizes.

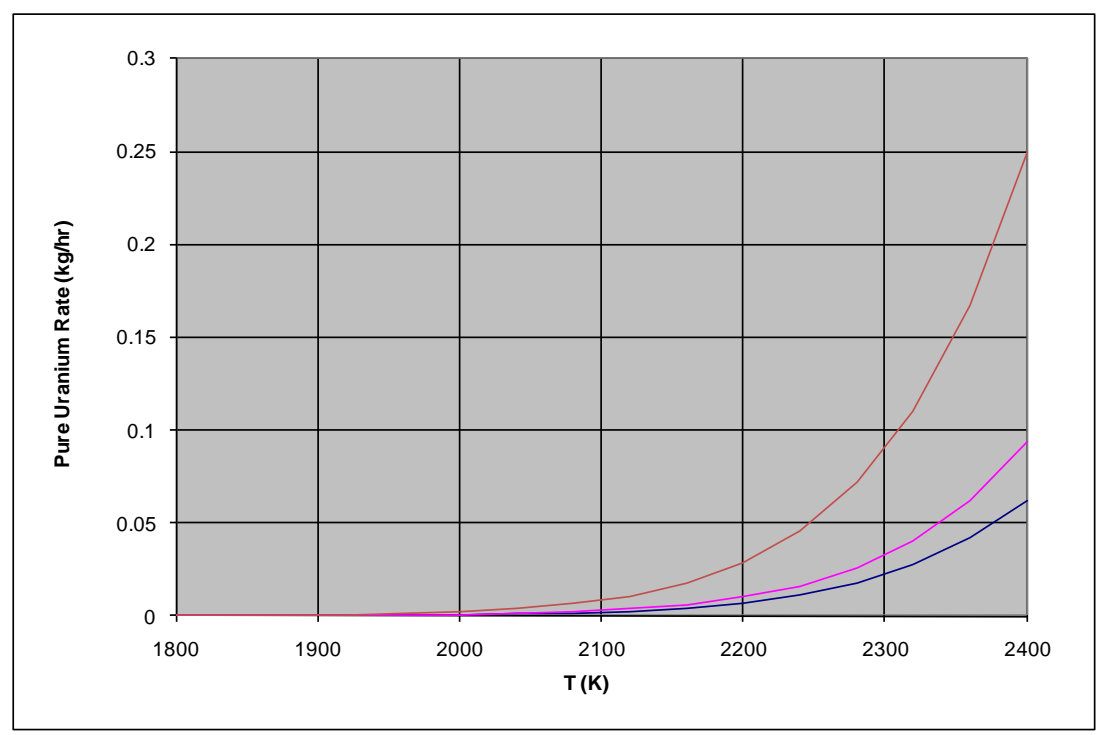

Figure 3. (Figure 2 from the Reference Document) Rate vs. temperature for a pure uranium casting melt with melt radius of $5,7.5$ and $10 \mathrm{~cm}$ from bottom curve to top. 
For a casting melt, depending on the melt and heating design, there may also be temperature and surface profiles which will have an impact on the vapor production. If details are required on the vapor production profile, a melt dynamics model is necessary. However since these melts are not designed for the purpose of vapor production and the vaporization is low, the use of an average temperature and size of the melt is adequate to determine vapor production estimates.

\section{Vapor Density}

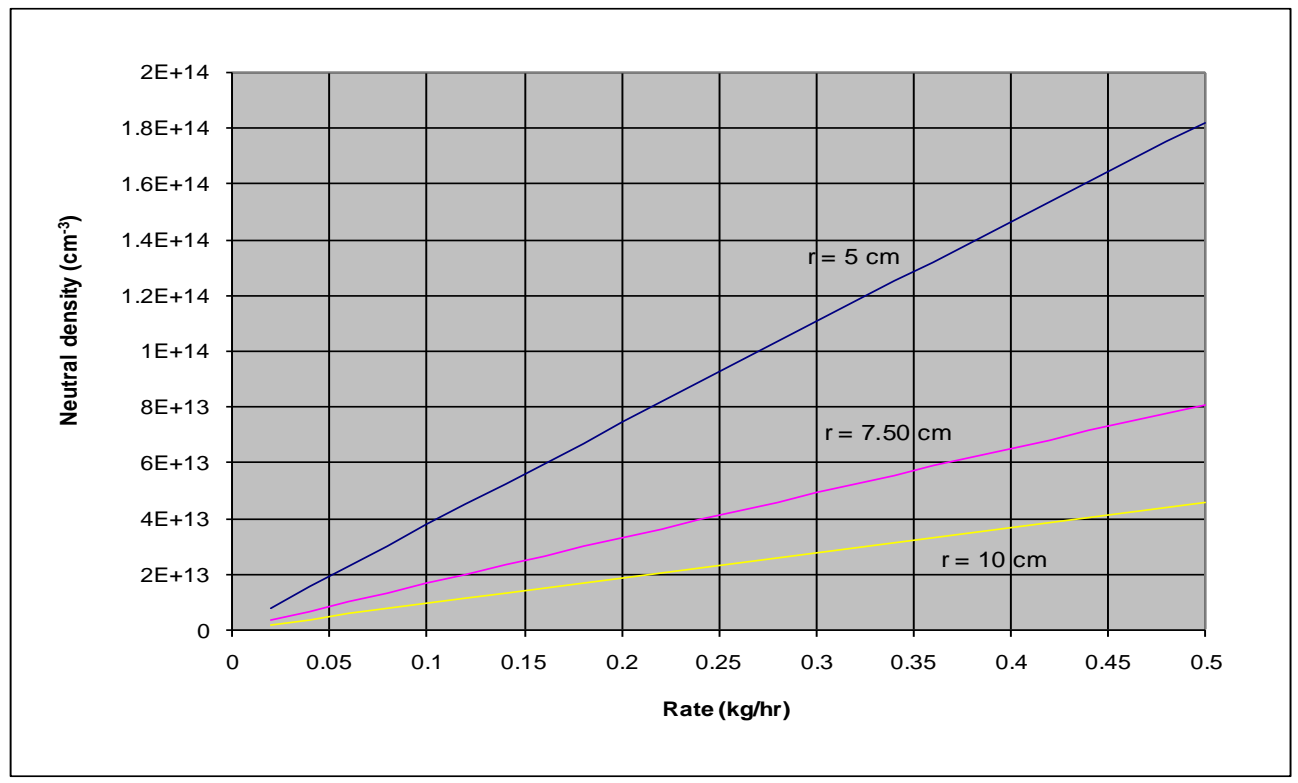

Figure 4. (Reference Figure 13) Neutral density of uranium at the casting source as a function of rate with the hot zone size as a parameter.

For a uniform temperature system an ideal gas law, $\mathrm{P}=\mathrm{nkT}$, can be used to estimate the uniform density throughout the system based upon the melt surface pressure shown in Figure 2. Note that by combining Equations 3,6,and 22 from the Reference Document, which apply to the melt surface, one obtains the equation $n=P / 2 k T$ for the density at the surface. This differs from the uniform system density, by a factor of 2 , which has vapor arriving at the surface from the rest of the system.

It is also convenient to approximate the neutral uranium density above the melt. Since at this point we have not presented any vapor flow modeling we assume two cases for the plot, a $r^{-1}$ scaling and a $r^{-2}$ scaling. Figure (5) shows these cases for four characteristic evaporation rates. The actual scaling probably lies between the two groups.

There are a number of ways that the quantity of Uranium in the vapor state can be estimated. For example, if we choose $0.5 \mathrm{~kg} / \mathrm{hr}$ for the $\mathrm{r}=5 \mathrm{~cm}$ melt from Figure 4, we find $\mathrm{U}$ density at the melt surface of about $1.8 \times 10^{+14}$ atoms $/ \mathrm{cm}^{+3}$. For an atomic mass of $3.98 \times 10^{-25} \mathrm{~kg} /$ atom this gives a density of $7.16 \times 10^{-11} \mathrm{~kg} / \mathrm{cm}^{+3}$ for a chamber with cold walls. If we assume that the vapor flows straight from the $r=5 \mathrm{~cm}$ melt to a wall 1 meter away, the total vapor mass is $562 \mu \mathrm{g}$. For a uniform temperature container of $\mathrm{r}=5 \mathrm{~cm}$ and a height of $10 \mathrm{~cm}$, we get the melt surface density of twice that for the cold walls. Thus $\mathrm{n}=1.43 \times 10^{-10} \mathrm{~kg} / \mathrm{cm}^{+3}$ and the vapor mass is $112 \mu \mathrm{g}$. 


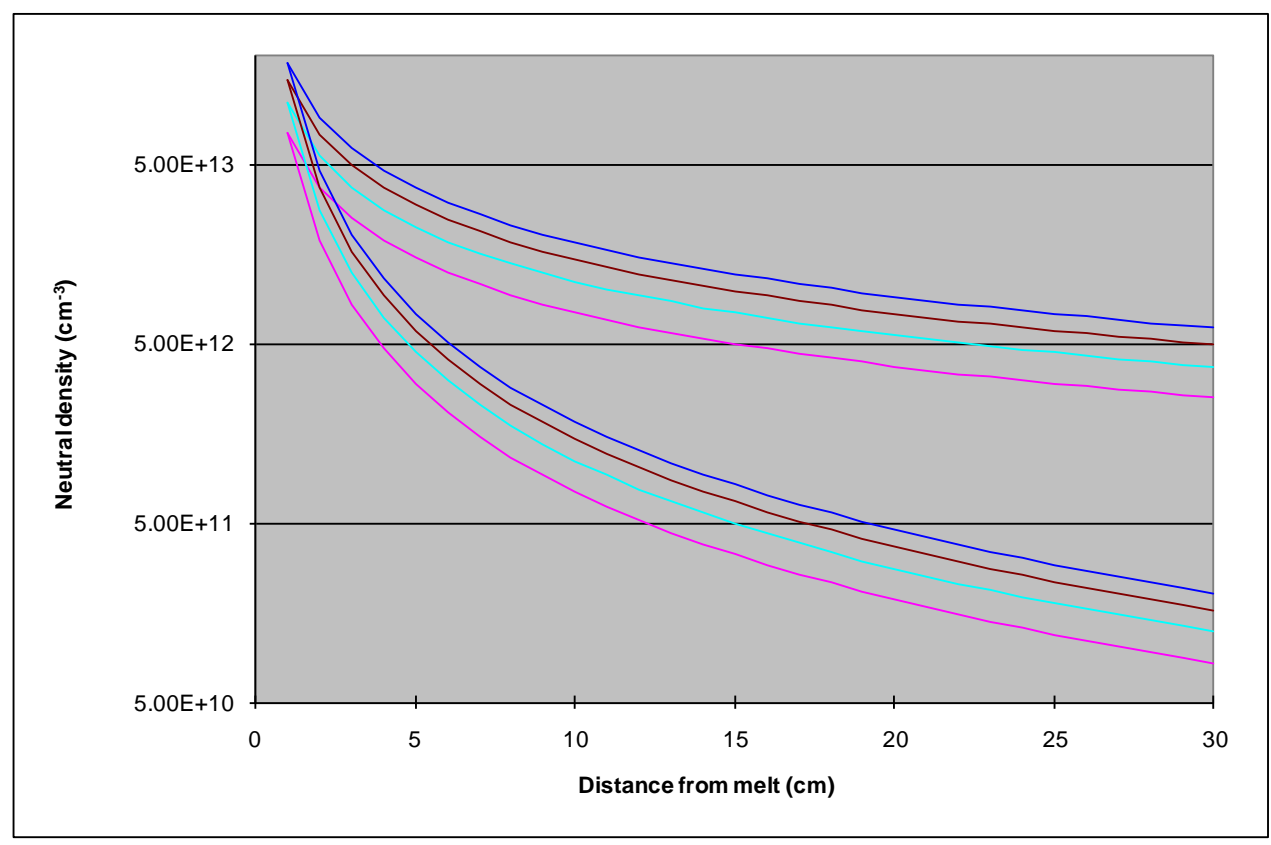

Figure 5. (Reference Figure 14) Neutral uranium density as a function of distance above the source for $0.5,0.4,0.3$ and $0.2 \mathrm{~kg} / \mathrm{hr}$, top to bottom, in two groups where the top group is for a $1 / \mathrm{r}$ and the bottom group is for a $1 / \mathrm{r}^{2}$ scaling.

Depending upon the design details of the melt system there are a number of things which can affect the vapor state. Background gas can react with the vapor forming heavier molecules which propagate differently. In the event of a system breach, the vapor reaction with air and the cold, damaged chamber components can reduce the release or $U$ vapor to surrounding areas. The cooling rate of the melt surface or the splashing of the melt liquid under extreme conditions may also play a part in determining vapor release. In general, the vapor estimates given here should give a reasonable estimate of overall possibility of release mass. 